\title{
A UTILIZAÇÃO DA MÚSICA “AQUI NO MAR” COMO ESTRATÉGIA PEDAGÓGICA PARA O ENSINO DE CIÊNCIAS E BIOLOGIA
}

\author{
The use of the song “Aqui no Mar” as a pedagogical strategy for Science and Biology \\ teaching
}

BRANDÃO, Lucas Esquivel Dias'; BARROS, Marcelo Diniz Monteiro²

\begin{abstract}
Resumo
Objetivando repensar e reavaliar a maneira como o ensino é realizado nas escolas e visando buscar novas metodologias que venham a aprimorar as formas tradicionais de ensino, foi desenvolvida uma atividade contendo 16 questões sobre a música "Aqui no Mar", interpretada por Diogo Nogueira, que pode ser trabalhada nas disciplinas de Ciências e Biologia. Espera-se que os professores de Ciências e Biologia tenham acesso a essa atividade e que possam, de acordo com os seus anseios, trabalhar os diferentes conteúdos biológicos que se fazem presentes na letra da música. Pretende-se, ainda, despertar a criatividade dos professores, de forma que os mesmos possam desenvolver outras atividades como essa em suas práticas educativas.
\end{abstract}

\begin{abstract}
Aiming to rethink and re-evaluate the way teaching is done in schools and seeking new approaches to improve traditional education forms, it was developed an activity containing 16 questions about the song "Aqui no Mar", sang by Diogo Nogueira, that can be worked in the Science and Biology disciplines. It is expected that the Science and Biology teachers have access to this activity and can, according to their proposals, work the different biological contents that are present in the lyrics. It is intended also to awaken the creativity of teachers, so that they can develop other activities like this in their educational practices.
\end{abstract}

Palavras-chave: Ensino de Biociências, Música como estratégia de ensino, "Aqui no mar".

Keywords: Biosciences Education, Music as a teaching strategy, “Aqui no Mar".

Data de submissão: Janeiro de 2016 | Data de publicação: Março de 2016.

\footnotetext{
${ }^{1}$ LUCAS DE ESQUIVEL DIAS BRANDÃO - Graduando do Curso de Ciências Biológicas da Pontifícia Universidade Católica de Minas Gerais, Belo Horizonte, Minas Gerais, Brasil. Correio Eletrónico: lucasdesquivel@hotmail.com.

${ }^{2}$ MARCELO DINIZ MONTEIRO DE BARROS - Professor Adjunto IV do Departamento de Ciências Biológicas da Pontifícia Universidade Católica de Minas Gerais, Belo Horizonte, Minas Gerais, Brasil. Correio Eletrónico: marcelodiniz@ pucminas.br.
} 


\section{INTRODUÇÃO}

Segundo a Lei $n^{\circ}$ 9.394/96, no $2^{\circ}$ parágrafo do artigo 1, a educação escolar deve vincular o conteúdo ministrado ao mercado de trabalho e à sociedade. Porém, mais de dezoito anos se passaram e o que percebemos atualmente é que o Ensino de Ciências e Biologia tem se dado, na maioria das vezes, por meio da transmissão de informações prontas apresentadas nos livros didáticos, não estimulando o raciocínio e a busca de soluções por parte dos alunos (SOBRINHO, 2009).

Atualmente, não se pode mais aceitar o ensino a partir da memorização. É necessário que os professores adotem metodologias alternativas e inovadoras em suas práticas pedagógicas, que venham propiciar ao aluno uma maior utilização do raciocínio (COSTA \& BARROS, 2014; SILVA et al., 2009).

Há mais de 30 anos a legislação brasileira estabelece um espaço para a arte e suas diversas linguagens na educação básica. Entretanto, mesmo a música sendo uma dessas linguagens, muitas vezes ainda é desvalorizada no ensino (MOURA, 2013).

Dentre tantos recursos didáticos que podem ser utilizados pelo professor a fim de oportunizar e facilitar o processo de aprendizado dos alunos, destaca-se no presente trabalho o uso da música em sala de aula.

Apesar da música não ilustrar visualmente o conteúdo que pode ser explorado, ela se constitui em um veículo de expressão que é capaz de aproximar mais o aluno do tema a ser estudado. Muitos são os benefícios de se utilizar músicas como recursos didáticopedagógicos nas aulas de Ciências e Biologia, dentre elas a saber: 1) É uma opção de baixo custo; 2) É um recurso de fácil assimilação; e 3) É uma atividade lúdica para os alunos (BARROS, ZANELLA, \& ARAÚJO-JORGE, 2013; BERTONCELLO \& SANTOS, 2002).

Visando contribuir para a melhoria no modo como o ensino é realizado nas escolas, o presente estudo acredita que a música pode ser utilizada como uma ferramenta eficiente, capaz de contextualizar os conteúdos, e desse modo, facilitar a aquisição dos saberes biológicos pelos alunos. Nesse viés, foi apresentada uma proposta para a utilização da canção "Aqui no mar" como uma alternativa para o ensino de Ciências e Biologia. 


\section{METODOLOGIA}

Foi elaborada uma atividade contendo 16 questões sobre a música “Aqui no mar", interpretada por Diogo Nogueira, que possui composição de Ashman e Menken (2010), que pode ser trabalhada nas disciplinas de Ciências e Biologia. É necessário que os docentes testem a atividade nos mais variados contextos educacionais, e se acharem necessário, que efetuem modificações na mesma, visando aproximar ainda mais o ensino de Ciências e Biologia da música popular brasileira.

\section{RESULTADOS}

Letra da música Aqui no mar, Composição: Howard Ashman e Alan Menken.

$$
\begin{aligned}
& \text { O fruto do meu vizinho } \\
& \text { Parece melhor que o meu } \\
& \text { O sonho de ir lá em cima } \\
& \text { Eu creio que é engano seu } \\
& \text { Você tem aqui no fundo } \\
& \text { Conforto até demais É tão } \\
& \text { belo o nosso mundo } \\
& \text { O que é que você quer mais? } \\
& \text { Onde eu nasci, onde eu cresci } \\
& \text { É mais molhado, eu sou vidrado por tudo } \\
& \text { aqui } \\
& \text { Lá se trabalha o dia inteiro } \\
& \text { Lá são escravos do dinheiro } \\
& \text { A vida é boa, eu vivo à toa } \\
& \text { Onde eu nasci } \\
& O \text { peixe vive contente } \\
& \text { Aqui debaixo do mar } \\
& \text { O peixe que vai pra terra } \\
& \text { Não sabe onde vai parar } \\
& \text { Às vezes vai pra um aquário } \\
& \text { O que não é ruim de fato } \\
& \text { Mas quando o homem tem fome } \\
& \text { O peixe vai para o prato }
\end{aligned}
$$

Vou lhe contar: Aqui no mar 
Ninguém nos segue nem nos persegue pra nos fritar

Se os peixes querem ver o sol

Tomem cuidado com o anzol

Até o escuro é mais seguro

Aqui no mar

Onde eu nasci

Neste oceano entra e sai ano

Tem tudo aqui

Os peixes param de nadar

Quando é hora de tocar

Temos a bossa que é toda nossa

Aqui no mar

Tritão sopra a flauta

E a carpa na harpa

A solha no baixo,

Melhor som não acho

E aqui nos metais

Tem peixe demais, espere que

temos mais

Ninguém toca mal,

nem o bacalhau $A$

truta dançando, o

preto cantando

Até o salmão vem para o salão

E olhem quem vem soprar

Aqui no mar, aqui no mar

Até a sardinha entra na minha e vem cantar

E se eles têm montes de areia

Nós temos coro de sereia

Qualquer molusco

Sempre que eu busco sabe tocar

Até a lesminha sai da conchinha $E$ vem dançar Caracolzinho tira um sonzinho, por isso a gente daqui é

quente

Faz um programa até na lama

Aqui no mar 


\section{Perguntas propostas:}

\section{Observando as estrofes: “O fruto do meu vizinho/ Parece melhor que o meu”.} Responda as três primeiras questões:

1) Descreva as formas existentes de dispersão de frutos na natureza por animais.

Sugestão de resposta: A dispersão de frutos por animais chama-se Zoocoria, e ocorre de três formas: I) Ingestão do fruto e liberação da semente (Endozoocoria), II) Transporte do fruto de forma consciente (Sinzoocoria). Ambos os casos estão relacionados com os frutos carnosos e coloridos, uma vez que, nesses casos, o animal está normalmente procurando uma forma de alimentar-se. III) Transporte de fruto acidentalmente (Epizoocoria). Normalmente não está associado à alimentação, e sim às estruturas que fazem com que os frutos prendam-se ao corpo do animal. Nesse caso, são comuns frutos com ganchos, espinhos e cascas adesivas, que se fixam facilmente (SANTOS, 2015).

2) Cite as diversas denominações dadas para a dispersão de frutos realizada por animais (Zoocoria) de acordo com o animal dispersor.

Sugestão de resposta: 1) Mirmecocoria - dispersão por formigas. 2) Ictiocoria dispersão por peixes. 3) Saurocoria - dispersão por répteis.4) Ornitocoria - dispersão por pássaros. 4) Mamaliocoria - dispersão por mamíferos.5) Quiropterocoria - dispersão por morcegos. 5) Antropocoria - dispersão pelo homem (SANTOS, 2015).

3) Cite e explique as partes que constituem a estrutura básica do fruto.

Sugestão de resposta: $O$ fruto, geralmente, possui pericarpo e semente. O pericarpo é dividido em três partes: epicarpo, mesocarpo e endocarpo. O epicarpo é a porção externa a casca. $\mathrm{O}$ mesocarpo é a parte muitas vezes carnosa e comestível. O endocarpo é a camada interna que envolve a semente.

4) No mundo contemporâneo as pessoas são, cada vez mais, classificadas pelo que possuem e pelo que consomem. A partir do trecho "Lá se trabalha o dia inteiro/Lá são escravos do dinheiro", discuta o que significa o consumismo e quais são os impactos ambientais causados por ele.

Sugestão de resposta: O consumismo é uma compulsão que leva o indivíduo a comprar de forma ilimitada e sem necessidade bens, mercadorias e/ou serviços. Um dos problemas causado pelo consumismo é o uso desenfreado dos recursos naturais que não 
são renováveis, como o petróleo, por exemplo, que cada vez mais está se esvaindo. O aumento no consumo de energia, água, minerais e elementos da biodiversidade vêm causando sérios problemas ambientais, como a poluição da água e do ar, a contaminação e o desgaste do solo, o desaparecimento de espécies animais e vegetais e as mudanças climáticas. Outro grande problema é o aumento da produção de lixo, que por sua vez, nem sempre possui um tratamento ou um local de descarte adequado, sendo levados para lixões a céu aberto (PORTAL, 2015).

5) Leia as estrofes : “O peixe vive contentel Aqui debaixo do mar”. A seguir cite a forma pela qual os peixes excretam seus produtos nitrogenados no ambiente marinho e como acontece a regulação da sua temperatura corporal.

Sugestão de resposta: Os produtos nitrogenados são excretados no ambiente marinho na forma de amônia, substância altamente tóxica e solúvel, que demanda grande quantidade de água para ser eliminada. Por isso esse tipo de excreta ocorre apenas em animais aquáticos, para os quais obter água não é um problema. Como são animais Ectotermos (heterotermos) a regulação da temperatura corporal varia de acordo com a temperatura do ambiente (POUGH et al., 2008).

6) “Os peixes param de nadar/Quando é hora de tocar”. A locomoção dos peixes na água é feita através do movimento de suas nadadeiras na água. Cite e explique cada tipo de nadadeira que existe neste grupo.

Sugestão de resposta: Há seis tipos de nadadeiras: a adiposa que não ocorre em todas as espécies (é desprovida de raios e tem finalidade desconhecida, localizada entre as nadadeiras dorsal e caudal); a anal que atua como uma quilha, dando equilíbrio ao peixe (localiza-se logo abaixo da caudal); a caudal que impulsiona o peixe na água. É a principal responsável pela sua propulsão na água e também tem influência sobre o equilíbrio. Há vários tipos: arredondada (tem a forma circular), bifurcada (tem a forma de um "V" deitado), confluente (assemelha-se a um pincel), crescente (tem o formato de uma lua), margeada (parece um semi-círculo com irregularidades na extremidade) e a truncada (tem a forma de um trapézio); a dorsal que tem basicamente a mesma função da anal, atuando como uma quilha. Com ela o peixe pode fazer curvas; a peitoral que têm várias funções: permitem que os peixes girem em torno de seu eixo, podem reduzir a velocidade de nado, movimentam a água próxima a ovos, para proporcionar uma oxigenação; deslocam alimento que esteja sobre o substrato; e a pélvica (ventral) (POUGH et al., 2008). 
7) Sobre o trecho "Tritão sopra a flauta e a carpa na harpa". A carpa é um peixe que vive em águas cálidas, rios de curso lento e lagos. Se alimenta de pequenos invertebrados e é muito usada em piscicultura. Explique qual é a importância da carpa para países orientais como China e Japão.

Sugestão de resposta: A carpa $^{3}$ significa boa sorte, sucesso, vida longa e perseverança, e é um peixe muito valorizado nesses países. Existe uma lenda chinesa que diz que a carpa tinha que atingir a fonte do Rio Amarelo, que atravessa todo o continente chinês, na época da desova, tendo que nadar e saltar vales cheios de cascatas até à montanha Jishinhan. A carpa que chegasse até o fim, se transformaria em dragão.

8) “A truta dançando, o preto cantando”. A carne da truta é indicada como coadjuvante no tratamento da artrite reumatoide e psoríase, impede enfartos do miocárdio, reduz os níveis de colesterol e triglicerídios e diminui a pressão sanguínea (hipertensão) e atenua estados inflamatórios. Escreva características nutricionais dessa espécie bem como outros benefícios a saúde.

Sugestão de resposta: A carne da truta ${ }^{4}$ possui alto valor nutritivo, com alto teor de proteína, cálcio, fósforo, sais minerais e vitaminas. Apresenta também ácidos graxos do tipo Ômega-3 e baixo teor de calorias, o que a torna uma boa opção para dietas de emagrecimento e na redução do colesterol ruim (LDL), nocivo ao coração. Ômega-3 é um suplemento alimentar indicado na prevenção primária e secundária da aterosclerose e da doença coronária.

9) Baseando-se nas estrofes: “Mas quando o homem tem fome/ O peixe vai para o prato"; explique, os benefícios da carne de peixe. Posteriormente, discuta porque a carne de peixe cozinha mais rápido que a carne de outros animais.

Sugestão de resposta: A carne de peixe possui grande quantidade de minerais (como cálcio e fósforo), vitaminas, e é rica em proteínas. Possui ômega-3 que ajuda a controlar a pressão, reduz o risco de doenças cardíacas, aterosclerose (endurecimento das artérias) e o nível de colesterol e triglicérides. "Cozinha mais rápido porque a estrutura muscular é diferente da dos mamíferos terrestres. Se comparada às outras carnes (bovina, suína e de aves), a carne de peixe tem menos quantidade de tecido conjuntivo, o que contribui para a maciez da sua textura. É por essa razão que a carne do pescado cozinha

\footnotetext{
${ }^{3}$ http://www.significados.com.br/carpa/>. Acesso em: 9/6/2015.

${ }^{4} \mathrm{http}: / / w w w . t r u t a . c o m . b r / s o b r e \_a \_t r u t a . h t m>$. Acesso em: 9/6/2015.
} 
mais rápido. Grosso modo, a estrutura muscular do peixe é arranjada de tal forma que os feixes de fibras se destacam em flocos após o cozimento. Já o teor de gordura do peixe ajuda a carne a reter uma parcela da umidade depois de cozida. Alguns exemplos de peixes gordos que podem apresentar teores de até $20 \%$ de gordura: mapará (típico da região Norte) e sardinha" (LOMBARDI, 2003).

10) Sobre o seguinte trecho: "Tritão sopra a flauta/ E a carpa na harpa"; explique quem foi Tritão na mitologia grega, quem é Tritão no sistema solar, e quem é tritão na biologia. A seguir, atribua qual o significado da carpa nos países orientais como China e Japão.

Sugestão de resposta: Tritão ${ }^{5}$, (Triton) na mitologia grega, é um deus marinho conhecido como o Rei dos Mares. Filho de Poseidon (Netuno na mitologia romana) e Anfitrite (Salácia), geralmente é representado com cabeça e tronco humanos e cauda de peixe É um fiel servidor de seus pais, atuando como seu mensageiro e acalmando as águas do mar para que a carruagem de Poseidon deslize com segurança.

Tritão $^{6}$ é também a maior lua de Netuno, que se encontra a cerca de 4500 milhões de quilômetros do Sol. É um dos astros mais gélidos do sistema solar, com uma história geológica bastante complexa; possui uma superfície bastante jovem e de aspecto rugoso, desfigurada por violentas erupções vulcânicas, rápidos congelamentos de superfície e com repentina fundição, gerando assim uma rede de rachaduras enormes. Na biologia, Tritão ${ }^{7}$ é o nome comum dado a anfíbios pertencentes à subfamília Pleurodelinae (família Salamandridae). Estão presentes em toda a Europa, Ásia, América do Norte e norte da África (WIKIPÉDIA, 2015c). Em países orientais, como Japão e China, a carpa é um peixe muito valorizado já que significa boa sorte, sucesso, vida longa e perseverança.

11) “Ninguém toca mal, nem o bacalhau/A truta dançando, o preto cantando/ Até o salmão vem para o salão". Explique o significado do termo "bacalhau do porto" utilizado em Portugal. Discuta, a seguir porque a truta pode ser vendida como salmão.

\footnotetext{
${ }^{5}<$ http://pt.wikipedia.org/wiki/Trit\%C3\%A3o_\%28mitologia\%29>. Acesso em: 30/3/2015.a.

${ }^{6}<$ http://pt.wikipedia.org/wiki/Trit\%C3\%A3o_\%28sat\%C3\%A9lite\%29>. Acesso em : 30/3/2015.b.

${ }^{7}<$ http://pt.wikipedia.org/wiki/Trit\%C3\%A3o_\%28anf\%C3\%ADbio\%29>. Acesso em: 30/3/2015.c.
} 
Sugestão de resposta: O peixe Gadus morhua é conhecido como bacalhau do Porto, uma referência à cidade portuguesa, apesar de não haver bacalhau em águas lusitanas. Portugal chegou a se tornar o maior mercado consumidor de bacalhau do mundo sendo um importante centro de comércio do peixe seco e salgado que chega do Atlântico Norte, em especial da Noruega (NOGUEIRA, 2004),

"A truta e o salmão integram a família dos salmonídeos e têm gosto bem parecido - só que a truta é mais barata. Por isso, há produtores que dão às trutas uma ração aditivada com corante, para que elas fiquem rosadas, visualmente idênticas ao salmão. Se a truta for consumida na forma de sushi, cortada e misturada com shoyu, é muito difícil notar diferença no sabor. O próprio salmão também é alimentado com corantes - porque, como é criado em cativeiro, não tem acesso aos crustáceos dos quais se alimenta na natureza, e que dão a ele sua cor rosada natural. Os criadores colocam na ração os pigmentos astaxantina e cantaxantina, que podem ser sintéticos ou extraídos de algas, afirma o engenheiro de alimentos Cláudio Lima" (SZKLARZ \& GARATTONI, 2012).

12) “Aqui no mar, aqui no mar/ Até a sardinha entra na minha e vem cantar”. Cite o principal item alimentar das sardinhas.

Sugestão de resposta: As sardinhas se alimentam principalmente de plâncton (CORNILS \& LACERDA, 2015).

13) “Qualquer molusco/ Sempre que eu busco sabe tocar”. Sabendo da existência do músculo adutor em alguns moluscos, explique porque conchas cruas são difíceis de ser abertas.

Sugestão de resposta: Simplesmente porque os organismos que vivem dentro delas estão vivos. Dos moluscos mais conhecidos na gastronomia, como o marisco ou mexilhão, a ostra, a vieira e o vôngole, consumimos o músculo adutor, também chamado de manto, que se agarra à concha. Enquanto o organismo está vivo, esse músculo preserva a concha fechada (LOMBARDI, 2003).

14) Quais são as vantagens e as desvantagens dos aquários?

Sugestão de resposta: Para os animais de aquário: 
Vantagens: $\mathrm{O}$ animal está submetido a um cuidado especial. $\mathrm{O}$ animal está livre de predadores, bem alimentado e sadio, pois as plantas colocadas no aquário devem estar livres de parasitas (DURREL \& DURREL, 1984).

Desvantagens: $\mathrm{O}$ animal está totalmente dependente do seu dono ou do mantedor do aquário. Neste caso, se houver um excesso de detritos no tanque, falta de alimento para os animais que ali habitam, déficit de oxigenação da água, entre outros, os indivíduos sofrerão (DURREL\& DURREL, 1984).

15) No mar, ninguém segue os seres para que possam fritá-los... mas seguem para outras finalidades?

Sugestão de resposta: Sim. Seguem para predá-los. Para isso, os animais lançam mão de variados métodos de captura. Exemplos disso são: a captura de material em suspensão (principalmente por parte dos invertebrados); a filtração, principalmente por parte dos vertebrados, a saber, os cetáceos misticetos, peixes ósseos, moluscos bivalves e até aves (HICKMAN et al., 2004); a captura por inteiro da presa durante a pesca (por parte de algumas aves); por sucção (POUGH et al., 2002) ou, como no caso dos cetáceos odontocetos, pela incapacitação das presas por meio de mordidas em locais estratégicos (como as nadadeiras, por exemplo) seguida pela deglutição desta por inteiro (DI BENEDITTO et al., 2010). Outros animais podem perseguir presas para se alimentarem de seus fluidos, como no caso de algumas lampreias (HICKMAN et al., 2004).

16) Você seria capaz de dividir os mais variados grupos de animais que aparecem de acordo com as categorias taxonômicas a que pertencem? Sugestão de resposta:

\begin{tabular}{|c|c|c|c|c|c|}
\hline Nome comum & Reino & Filo & Classe & Ordem & Família \\
\hline TRITÃO & Animalia & Chordata & Amphibia & Caudata & Salamandridae \\
\hline CARPA & Animalia & Chordata & Actinopterygii & Cypriniformes & Cyprinidae \\
\hline TRUTA & Animalia & Chordata & Actinopterygii & Salmoniformes & Salmonidae \\
\hline SOLHA & Animalia & Chordata & Actinopterygii & Pleuronectiformes & Soleidae \\
\hline SALMÃO & Animalia & Chordata & Actinopterygii & Salmoniformes & Salmonidae \\
\hline BACALHAU & Animalia & Chordata & Actinopterygii & Gadiformes & Gadidae \\
\hline SARDINHA & Animalia & Chordata & Actinopterygii & Clupeiformes & Clupeidae \\
\hline $\begin{array}{c}\text { LESMINHA/ } \\
\text { CARACOLZINHO* }\end{array}$ & Animalia & Mollusca & Gastropoda & - & - \\
\hline
\end{tabular}

Fontes da tabela 1: Chumchal (2002), Dewey (2015a,b), Larson et. al (2006), Ridolfi (2006), Roberts (2000), Ryan (2014), Wilmot (2005). *Lesma e caracol são palavras genéricas que designam popularmente moluscos da classe Gastropoda. 


\section{DISCUSSÃO}

Belisário et al. (2013) demonstraram como contextualizar os conteúdos de botânica e história através da música "Tanto Mar”, de Chico Buarque. Por meio dessa música, os professores de Biologia e de História, da educação básica, podem pedir aos seus alunos que procurem se aprofundar na temática do Dia da Liberdade e, façam uma produção de texto acerca desse acontecimento; que caracterizem o período conhecido como a Primavera Marcelista; que investiguem um movimento popular, que tenha ocorrido em Portugal ou no Brasil, e descrevam seus aspectos mais importantes; podem também explicar a importância do embrião de uma planta para o seu estabelecimento na terra. Da mesma maneira, podem solicitar aos estudantes que representem o ciclo reprodutivo de uma fanerógama, identificando a fase gametofítica e a esporofítica; que elaborem um texto destacando o valor das algas, de maneira ampla, associando as mesmas ao mar; que façam uma reflexão sobre a importância das plantas e partes das mesmas no nosso dia-a-dia, nas nossas conquistas, na manutenção da biodiversidade, na manutenção da vida; dentre outros aspectos possíveis de se explorar na letra da música.

Barros, Diniz e Araujo-Jorge (2014a) demonstram como descobrir ciências em letras de músicas. Focando nos eixos temáticos Terra e Universo/ Tecnologia e Sociedade, os autores sugerem, dentre várias, utilizar a música "Carimbador maluco", de Raul Seixas. As discussões propostas são : Na música, onde é que as pessoas pensam que vão?; Viajar de um país a outro é mais fácil... Podemos ir de avião, navio, de carro entre outros meios de transporte. Por que é mais difícil viajar pelo universo?; Quais condições são responsáveis por dificultar esse trajeto; Além do sol e da lua, o que mais você conhece em relação a Terra e ao Universo?; Que aventuras você gostaria de experimentar?, Dentre outras discussões possíveis. Para a canção "Lindo balão azul”, de Guilherme Arantes, sugerem trabalhar : o que é viver no mundo da lua?; Os papos dos cientistas são futuristas e lunáticos?, Que outros papos eles tem?; Como é a alma do artista?; É possível pegar carona na cauda de um cometa?; O que é a Via Láctea?; O que seria o balão azul?; O que a expressão voltar pra casa quer dizer?, entre outros tópicos.

Brandão et al. (2014) mostraram como estudar botânica através da música "Feira de Mangaio" escrita por Sivuca e Glorinha Gadelha (1979). Trata-se de um clássico da música nordestina, que apresenta os produtos que são comercializados pelos mangaieiros nas feiras livres, que podem ser entendidas como verdadeiros celeiros culturais. Evidencia, ainda, as manifestações artísticas que compõem o modo de vida das pessoas 
que transitam por estas feiras. Através da canção, recomenda-se que os professores de Ciências, das séries finais do Ensino Fundamental, e Biologia, do Ensino Médio, possam trabalhar com os alunos a associação entre as culturas fumageira e tabagista e a saúde humana; que possam associar o milho, o amendoim, a cana de açúcar e o coco verde, às suas respectivas classes vegetais e aos diferentes tipos de reprodução; que possam compreender a interação existente entre plantas e aves e sua importância para a botânica; que aprendam e discutam o significado das diferentes expressões nordestinas; que entendam a importância das feiras de mangaio para o sustento das famílias nordestinas, entre outros aspectos retratados pela rica letra da música.

Através da poesia "Solar", de Milton Nascimento e Fernando Brant, ainda para o tema Terra e Universo/ Tecnologia e Sociedade, pode-se trabalhar os seguintes aspectos: O que significa a expressão venho do sol?; É possível existir vida no planeta Terra sem o sol?; Por que é triste não ter o sol todo dia?; O que acontece nesse caso, quando o sol "não está lá”?; O que pode ser o inverno azul? (BARROS, DINIZ, \& ARAUJO-JORGE, 2014a). Para a poesia "Sobradinho", de Sá e Guarabyra, recomenda-se discutir : Como o homem desfaz a natureza?; O sertão vai virar mar?, O mar vai virar sertão?; Quem é o beato que dizia que o sertão ia alagar?; O que significa a expressão "vem o rio te engolir"?; "O povo vai embora com medo de se afogar". Para onde o povo vai embora?, Como esse processo acontece? Na poesia "Rosa de Hiroshima", de Vinícius de Moraes e Gérson Conrad, pode-se perguntar aos alunos: O que é a Rosa de Hiroshima?; Mudas, cegas, feridas... em consequência de que?; Porque a rosa é estúpida e inválida?; O que significa cirrose?, Em que condições ela pode ocorrer?. E por fim, para a música "Pombo correio", de Moraes Moreira, seria interessante discutir quais características biológicas podem fazer do pombo correio um mensageiro em potencial; Que situações poderiam provocar esse desencontro citado na música?; Voar o mundo se preciso for... o pombo correio pode voar a que distâncias?; Será que o pombo correio ainda é muito usado no mundo nos dias de hoje?; E outras tecnologias, como o Código Morse? (BARROS, DINIZ, \& ARAUJO-JORGE, 2014a).

É bastante comum o fato de que alguns alunos nem sempre reconhecem a relação entre o que estudam, seus próprios conhecimentos e o quotidiano em que vivem. Assim sendo, interpretam que a Biologia se resume a memorização de nomes complexos, classificação de fenômenos e resolução de problemas que não fazem parte do seu dia-adia. Para mudar esse pensamento, é preciso que o Ensino de Biologia seja feito de uma 
forma contextualizada e interdisciplinar (BUSATO, 2001; MORAIS, 2004; ROSA \& OREY, 2014).

Contribuindo para o que foi relatado anteriormente, Barros, Diniz e Araujo-Jorge (2014b), para a temática Ser Humano e Saúde/ Vida e Ambiente, sugerem discutir os seguintes aspectos na poesia infantil "Ai meu nariz”, de Alvaréz, Bermudéz e Edgard Poças: O que pode provocar o funga funga da música?; Acupuntura... o que isso significa?; Como evitar que novas crianças fiquem com resfriado?; Por que o nariz fica se parecendo com um chafariz?. Na poesia de Edu Lobo e Chico Buarque, intitulada "Ciranda da bailarina", pode-se discutir quais são os grupos de seres vivos que aparecem na música; O que pode provocar piriri?; Por que as pessoas tem remelas quando acordam?; A bailarina possui algum tipo de problema, doença ou dificuldade?; A música pode permitir uma reflexão acerca dos hábitos de higiene... quais atitudes podem ser adotadas pelas pessoas para que a saúde fique cada vez melhor?, dentre outras possibilidades.

Ainda de acordo com os mesmos autores, para a música "Tudo vira bosta", de Moacyr Franco, seria relevante discutir com os alunos o trajeto dos alimentos em nosso corpo, até a formação das fezes. Ao utilizar o trecho ninguém vai escapar do pó... explicar o que isso significa. Ao utilizar a poesia de Chico Buarque e Francis Hime, na música "Passaredo", interessante seria, debater sobre: Por que os autores pedem aos animais para se afastarem de alguma forma quando o homem se aproxima?; Os nomes dos animais listados na música pertencem a qual grupo de vertebrados?; O que pode acontecer aos animais se eles não ficarem atentos?, etc. Para a poesia "O cio da terra", de Milton Nascimento e Chico Buarque, pode-se polemizar qual é a relação entre o trigo e o milagre do pão; O que significa debulhar e forjar; Quais são os desejos da terra; O que quer dizer "cio da terra"; Como podemos fecundar o chão do Brasil; A cana e o mel são alimentos que possuem muitos açúcares... você conseguiria indicar mais alguns alimentos ricos nesse tipo de nutriente?. E, por fim, para a poesia de Gordurinha, "Vendedor de caranguejo", aconselha-se abordar: qual é o tipo de ambiente em que encontramos caranguejos?; O que é um gordo guaiamum?; Os caranguejos podem ser vendidos em cordas... você ou alguém da sua família já comprou os animais dessa forma?; Por que o vendedor perdeu a mocidade com os pés sujos de lama?; O que é e para que serve um caçuá?; O que significa a expressão "os bichinho tão criado”?, Dentre outros aspectos 
possíveis de se explorar na letra da poesia (BARROS, DINIZ, \& ARAUJO-JORGE, 2014b).

Brandão et al. (2015) registram como é possível aproximar os conteúdos botânicos para os alunos através da música "Espatódea", escrita por Nando Reis em homenagem a sua filha Zoé. Através dessa música, sugere-se que o professor trabalhe com os alunos a relação entre a distribuição geográfica da Spathodea campanulata (P. Beauv) e os usos medicinais desta planta em cada região; As prováveis consequências que essa espécie vegetal pode provocar nas áreas onde foi introduzida; Os nomes populares para a Espatódea; O motivo da árvore ser conhecida como xixi de macaco; Informações botânicas: tipo de inflorescência, tipo de fruto, função das flores na ornitofilia, nomes de componentes florais e suas respectivas funções, pigmentos responsáveis pelas cores vermelhas, laranjas e raramente amareladas das flores. A letra da música foi ricamente explorada, por exemplo no sentido de questionar o aluno sobre o órgão reprodutor que o gineceu representa e quais os diferentes recursos de atração adotados pelas flores, a partir da estrofe "Espatódea, gineceu cor de pólen”. Os discentes também podem criar grupos de discussão e propor hipóteses para explicar a toxicidade do néctar da planta; dentre outras perspectivas possíveis de se explorar.

Para contextualizar o tema Saúde/ Orientação sexual/ Meio Ambiente, Barros, Diniz e Araujo-Jorge (2014c), sugerem utilizar a canção "Exaustino", de Roberto Lopes, Canário e Nilo Penetra; a poesia infantil "De umbigo a umbiguinho", de Toquinho e Elifas Andreato; a música "O mundo é um moinho", de Cartola; a poesia "Flor da idade", de Chico Buarque; a poesia "O sal de Terra", de Beto Guedes e Ronaldo Bastos; e finalizam recomendando utilizar a poesia infantil "Herdeiros do futuro", de Toquinho e Elifas Andreato. Para debater o tema Ética/ Pluralidade Cultural/ Trabalho e Consumo; Barros, Diniz e Araujo-Jorge (2014d) defendem aproveitar a canção "Coração de estudante", de Wagner Tiso e Milton Nascimento; a poesia "Uma canção desnaturada", e "Assentamento", ambas de Chico Buarque; a música "A violeira”, de Tom Jobim e Chico Buarque; a canção "Sapato velho”, de Mu, Cláudio Nucci e Paulinho Tapajós; e encerram com a música "Bolsa de grife", de Vanessa da Mata.

No tema Ciência e Arte, Barros, Diniz e Araujo-Jorge (2014e) disponibilizam atividades que contextualizam esse assunto na poesia "A ciência em si”, de Gilberto Gil e Arnaldo Antunes; na música "Ciência e Arte", de Cartola e Carlos Cachaça; na poesia "Emergindo da Ciência", de Arnaldo Baptista; e na poesia "Quanta", de Gilberto Gil. Já 
para contextualizar o tema "Brasil sem Miséria”, Barros, Diniz e Araujo-Jorge (2014f) aconselham usar a música "Haiti”, de Gilberto Gil e Caetano Veloso; o pagode "Caviar", de Luiz Grande, Barbeirinho do Jacarezinho e Marcos Diniz, interpretado por Zeca Pagodinho; a poesia "O Meu Guri”, de Chico Buarque; a música "Burguesinha", interpretada por Seu Jorge; o rock "Miséria", de Arnaldo Antunes, Sérgio Britto e Paulo Miklos; a poesia "Pobreza por pobreza", de Luiz Gonzaga Jr.; e concluem com a música "Problema social", de Guará e Fernandinho.

A sociedade atual vive em um mundo bastante dinâmico, repleto de informações, que permitem a aquisição do conhecimento de uma maneira rápida. Considerando esse contexto, é necessário repensar e reavaliar a maneira como o ensino é realizado, bem como buscar novas metodologias que venham a aprimorar as formas tradicionais de ensino (OLIVEIRA \& SILVA, 2013; FORSTHUBER et al., 2011; BAÏDAK \& COGHLAN, 2006).

Sendo assim, espera-se que os professores de Ciências e Biologia tenham acesso a essa atividade e que possam, de acordo com os seus anseios, trabalhar os diferentes conteúdos biológicos que se fazem presentes na letra da música “Aqui no mar". Pretendese, ainda, despertar a criatividade dos professores, de forma que os mesmos possam desenvolver outras atividades como essa, em suas práticas educativas. 


\section{REFERÊNCIAS BIBLIOGRÁFICAS}

ASHMAN, H.; \& MENKEN, A. (2010). Aqui no Mar” (Under the Sea). In: Disney Adventures in Samba. Walt Disney Records. 1 CD - ROM. Faixa 6. Intérprete: Diogo Nogueira.

BAÏDAK, N.; \& COGHLAN, M. (2006). O Ensino das Ciências nas Escolas da Europa: Políticas e Investigação. Europa: Agência de Execução relativa à Educação, ao Audiovisual e à Cultura (EURYDICE).

BARROS, M. D. M.; DINIZ, P. G. Z.; \& ARAUJO-JORGE, T. C. (2014). Descobrindo ciências em letras de músicas 1- Ciência e Arte em oficinas dialógicas de música. Rio de Janeiro: Com Ciência e Arte na Escola@ LITEB/IOC/Fiocruz.

BARROS, M. D. M.; DINIZ, P. G. Z.; \& ARAUJO-JORGE, T. C. (2014). Descobrindo ciências em letras de músicas 2- Brasil sem Miséria em oficinas dialógicas de música. Rio de Janeiro: Com Ciência e Arte na Escola@ LITEB/IOC/Fiocruz.

BARROS, M. D. M.; DINIZ, P. G. Z.; \& ARAUJO-JORGE, T. C. (2014). Descobrindo ciências em letras de músicas 3-Terra e Universo/ Tecnologia e Sociedade em oficinas dialógicas de música. Rio de Janeiro: Com Ciência e Arte na Escola ( LITEB/IOC/Fiocruz.

BARROS, M. D. M.; DINIZ, P. G. Z.; \& ARAUJO-JORGE, T. C. (2014). Descobrindo ciências em letras de músicas 4-Ser Humano e Saúdel Vida e Ambiente em oficinas dialógicas de música. Rio de Janeiro: Com Ciência e Arte na Escola $\odot$ LITEB/IOC/Fiocruz.

BARROS, M. D. M.; DINIZ, P. G. Z.; \& ARAUJO-JORGE, T. C. (2014). Descobrindo ciências em letras de músicas 5-Saúde/ Orientação Sexual/ Meio Ambiente em oficinas dialógicas de música. Rio de Janeiro: Com Ciência e Arte na Escola ( LITEB/IOC/Fiocruz.

BARROS, M. D. M.; DINIZ, P. G. Z.; \& ARAUJO-JORGE, T. C. (2014). Descobrindo ciências em letras de músicas 6- Ética/ Pluralidade Cultural/ Trabalho e Consumo em oficinas dialógicas de música. Rio de Janeiro: Com Ciência e Arte na Escola ( LITEB/IOC/Fiocruz.

BARROS, M. D. M.; ZANELLA, P. G.; \& ARAUJO-JORGE, T. C. (2013). A MÚSICA PODE SER UMA ESTRATÉGIA PARA O ENSINO DE CIÊNCIAS NATURAIS? 
ANALISANDO CONCEPÇÕES DE PROFESSORES DA EDUCAÇÃO BÁSICA. Revista Ensaio, Belo Horizonte, 15 (01), p. 81-94.

BELISÁRIO, R. et al. (2013). DISCUTINDO A REVOLUÇÃO DOS CRAVOS NOS CONTEXTOS DA BOTÂNICA E DA HISTÓRIA NA EDUCAÇÃO BÁSICA, A PARTIR DA MÚSICA “TANTO MAR”, DE CHICO BUARQUE (1978). Trabalho apresentado ao $64^{\circ}$ Congresso Nacional de Botânica, Belo Horizonte.

BERTONCELlO, L.; \& SANTOS, M. R. (2002). Música aplicada ao ensino da informática em ensino profissionalizante. Iniciação Científica CESUMAR, Maringá, 4(2), p. 131-142.

BRANDÃO, L. E. D. et al. (2015). A UTILIZAÇÃO DA MÚSICA "ESPATÓDEA" COMO ESTRATÉGIA PARA O ENSINO DE BOTÂNICA: APROXIMAÇÕES COM O ENSINO DE CIÊNCIAS E BIOLOGIA. Trabalho apresentado ao $66^{\circ}$ Congresso Nacional de Botânica, Santos.

BRANDÃO, L. E D. et al. (2014). ENSINANDO BOTÂNICA A PARTIR DA MÚSICA FEIRA DE MANGAIO DE SIVUCA E GLORINHA GADELHA (1979). Trabalho apresentado ao XI Congreso Latinoamericano de Botánica /LXV Congresso Nacional de Botânica, Salvador.

BRASIL. Lei $n^{\circ}$ 9.394, de 20 de dezembro de 1996. Estabelece as diretrizes e bases da educação nacional. Diário Oficial da União, Brasília, 20 de dezembro de 1996. Disponível em: <http://www.planalto.gov.br/ccivil_03/leis/19394.htm>. Consultado em: 22-022015 .

BUSATO, I. R. H. (2001). Desenvolvimento de metodologia adequada à disciplina de Biologia, que permita uma diminuição da visão fragmentada do saber e contemple uma visão mais integrada e holística. Dissertação (Mestrado em Engenharia de Produção) Programa de Pós-Graduação em Engenharia de Produção da Universidade Federal de Santa Catarina, Florianópolis.

CHUMCHAL, M. (2002). Cyprinus carpio (on-line), Diversidade de Animais Web. Disponível em: <http://animaldiversity.org/accounts/Cyprinus_carpio/>. Consultado em: 07-06-2015. 
CORNILS, P.; \& LACERDA, M. (2015). O fim das sardinhas. Disponível em: < http://super.abril.com.br/ecologia/fim-sardinhas-444191.shtml>. Consultado em: 30-32015.

COSTA, E. C. P.; \& BARROS, M. D. M. (2014). Luz, câmera, ação: o uso de filmes como estratégia para o ensino de Ciências e Biologia. REVISTA PRÁXIS, VI (11), p 8193.

DEWEY, T. (2015a). Salmonidae (On-line), Animal Diversity Web. Disponível em:

<http://animaldiversity.org/accounts/Salmonidae/>. Consultado em: 07-07- 2015.

DEWEY, T. (2015b). Clupeidae (On-line), Animal Diversity Web. Disponível em: $<$ http://animaldiversity.org/accounts/Clupeidae/>. Consultado em: 7-07-2015.

DI BENEDITTO, A. P. M.; SICILIANO, S.; \& RAMOS, R. M. A. (2010). Cetáceos: introdução à biologia e a metodologia básica para o desenvolvimento de estudos. Rio de Janeiro: Fundação Oswaldo Cruz; Escola Nacional de Saúde Pública.

DURREL, G.; \& DURREL, L. (1984). O naturalista amador: um guia prático ao mundo da natureza. São Paulo: Martins Fontes.

FORSTHUBER, B.; MOTIEJUNAITE, A.; COUTINHO, A. S. A.; BAÏDAK, N.; \& HORVATH, A. (2011). O Ensino das Ciências na Europa: Políticas Nacionais, Práticas e Investigação. Europa. Agência de Execução relativa à Educação, ao Audiovisual e à Cultura (EURYDICE).

HICKMAN, C. P.; ROBERTS, L. S.; \& LARSON, A. (2004). Princípios integrados de zoologia, 11. a ed. Rio de Janeiro: Guanabara Koogan.

LARSON; A.; WAKE, D.; \& DEVITT, T. (2006). Caudata. Disponível em:

<http://tolweb.org/Caudata/14939/2006.09.05>. Consultado em: 07-07-2015.

LOMBARDI, R. (2003). Peixes e frutos do mar. Superinteressante.

Disponível em: < http://super.abril.com.br/alimentacao/peixes-frutos-mar443895.shtml>. Consultado em : 30-3-2015.

MORAIS, P. L.L. (2004). A competência dos professores de Biologia em contextualizar os conteúdos específicos. Dissertação apresentada ao curso de Mestrado do Programa de Pós Graduação em Educação da Universidade Federal de Pernambuco, como requisito parcial para a obtenção do grau de mestre em Educação. Recife. 
MOURA, H. B. (2013). A Lei $\mathrm{n}^{\circ} 11.769 / 2008$ e sua aplicabilidade no ensino básico. Cadernos para o Professor, Juiz de Fora, 20, p. 9-17.

NOGUEIRA, M. (2004). Bacalhau é um peixe?. Superinteressante. Disponível em : < http://super.abril.com.br/mundo-animal/bacalhau-peixe444448.shtml>. Consultado em: 30-3-2015.

OLIVEIRA, V. D. R. B.; \& SILVA, M. R. (2013). As dificuldades da contextualização histórica no ensino de biologia. Trabalho apresentado ao EREBIO-Sul - VI Encontro Regional Sul de Ensino de Biologia/ XVI Semana Acadêmica de Ciências Biológicas. Universidade Regional Integrada do Alto Uruguai e das Missões - campus de Santo Ângelo (URI), 22 a 24 de maio de 2013.

PORTAL EDUCAÇÃO - Cursos Online. Disponível em: <http://www.portaleducacao.com.br/biologia/artigos/48472/o-consumismo-eseusimpactos-ambientais\#\#ixzz3Vv0qV100>. Consultado em: 9-6-2015.

POUGH, H. F; JANIS, C. M.; \& HEISER, J. B. (2008). A vida dos vertebrados, 4. ${ }^{\text {a ed. }}$ São Paulo: Atheneu.

POUGH, H. F; JANIS, C. M; \& HEISER, J. B. (2002). A vida dos vertebrados, 3. a ed. São Paulo: Atheneu.

RIDOLFI, K. (2006). Oncorhynchus mykiss (On-line), Animal Diversity Web. Disponível em: <http://animaldiversity.org/accounts/Oncorhynchus_mykiss/>. Consultado em: 0707- 2015 .

ROBERTS, J. (2000). Salvelinus fontinalis (On-line), Animal Diversity Web. Disponível em: <http://animaldiversity.org/accounts/Salvelinus_fontinalis/>. Consultado em: 07-072015.

ROSA, M.; \& OREY, D. C. (2014). APROXIMANDO DIFERENTES CAMPOS DE CONHECIMENTO EM EDUCAÇÃO: A ETNOMATEMÁTICA, A ETNOBIOLOGIA E A ETNOECOLOGIA. VIDYA, Santa Maria, 34 (1), p. 1-14. RYAN, C. (2014). Salmo trutta (on-line), Diversidade de Animais Web. Disponível em: $<$ http://animaldiversity.org/accounts/Salmo_trutta/>. Consultado em: 07-07- 2015. 
SANTOS, V. S. (2015). Dispersão de frutos e sementes. Disponível em : < http://www.alunosonline.com.br/biologia/dispersao-frutos-sementes.html>. Consultado em: 26-3-2015.

SILVA, R. P. et al. (2009). Ensino de Ciências e Biologia na escola pública: o que dizem os educandos de seu processo formativo. Trabalho apresentado ao IX CONID CONGRESSO DE INICIAÇÃO À DOCÊNCIA, Recife, 2009.

SOBRINHO, R. S. (2009). A importância do ensino da biologia para o cotidiano. Monografia apresentada como requisito parcial para obtenção do título de Licenciado em Biologia. Programa Especial de Formações de Docentes da Faculdade Integrada da Grande Fortaleza, Fortaleza - CE.

SZKLARZ, E.; \& GARATTONI, B. (2012). 25 coisas que estão escondendo de você: O salmão que você come nem sempre é salmão. Superinteressante. Disponível em : < http://super.abril.com.br/cotidiano/25-coisas-estao-escondendo-voce717510.shtml>. Consultado em : 30-3-2015.

WIKIPÉDIA (2015). http://pt.wikipedia.org/wiki/Trit\%C3\%A3o_\%28mitologia\%29>. Consultado em: 30-3-2015.

WILMOT, C. (2005). Gadus morhua (On-line), Animal Diversity Web. Disponível em: $<$ http://animaldiversity.org/accounts/Gadus_morhua/>. Consultado em: 07-07-2015. 